\title{
The use of meeting tools to make an online event: The CTRL+E experience
}

\author{
Elizabet M. Spohr de Medeiros ${ }^{1}$, Kely D. V. Villacorta ${ }^{1}$, Felipe A. G. Moreno ${ }^{1}$, \\ Artur I. A. Salviano², Matheus Gomes Silva², João Victor Pedrosa², Daniel de \\ Queiroz Cavalcanti' ${ }^{2}$, Matheus W. T. Nascimento ${ }^{3}$ \\ ${ }^{1}$ Departamento de Computação Científica - Centro de Informática \\ Universidade Federal da Paraíba (UFPB) - João Pessoa - PB - Brazil \\ ${ }^{2}$ Centro de Informática - Universidade Federal da Paraíba (UFPB) - João Pessoa - PB - \\ Brazil \\ ${ }^{3}$ Centro de Ciências Exatas e da Natureza - Universidade Federal da Paraíba (UFPB) - \\ João Pessoa - PB - Brazil

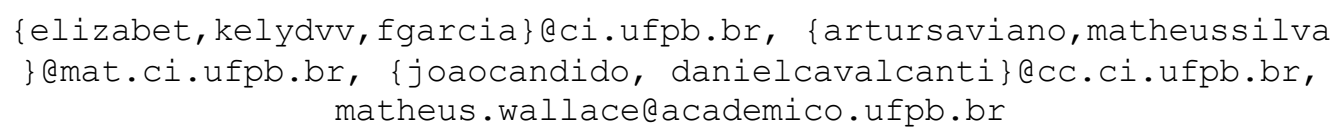

\begin{abstract}
This article describes the experience acquired in the use of tools for recording remote meetings, video editing and transmissions used in the execution of CTRL + E 2020, transforming it into a 100\% online event.
\end{abstract}

\section{Introduction}

The V Congress about Technologies in Education (CTRL+E 2020) [CTRL+E 2020 homepage] was a scientific event that took place from 25 to 28, August, 2020. Its aim was to bring together teachers, students, researchers and other professionals interested in the use of Technologies to support teaching and learning in different areas of knowledge. In this edition, the event's theme was Future Education: Technologies and People to Transform the World.

The first thought was to make the CTRL+E 2020 a live event in João Pessoa - Paraíba Brazil hosted by the Federal University of Paraíba - UFPB, following what happened in the previous editions of the CTRL+E; but, due to the pandemic generated by the SARS-CoV-2 spreader of COVID-19, it was necessary to study viable solutions to make the event happen remotely [Bezerra et al. 2020; Pires 2020]. The programme of CTRL+E had lectures, round tables, technical sections and demonstration sections. Our focus was to find new options for remote teaching, exploring the educational computational resources available in order to assist in the execution of CTRL+E 2020, transforming it into a $100 \%$ online event. It was necessary to use a comparison methodology to evaluate the tools for virtual meetings and lives available, in march and april 2020, in order to choose which of them would be the most suitable for the event. After choosing the tool, we started the task of recording and editing the presentations in video of each paper accepted for the event, and subsequently the task of formatting and transmitting the videos and lives of CTRL+E 2020. Technical coordination was assumed to analyze pros and cons of each participant's remote participation in the event. 
The present work is divided into 5 sections: in the first section we will approach the evaluation of the tools for virtual meetings and lives; in the second section we will discuss the recording and editing video procedures for CTRL+E 2020, in the third section we present the formatting and transmission of CTRL+E 2020 videos and lives, then we present our conclusions and references.

\section{Evaluation of tools for virtual meetings and lives}

Virtual meetings and lives are means of communication that have gained greater prominence in the context of social isolation, as their use has become indispensable in many cases e.g. [Porpiglia et al. 2020; Correia et al 2020]. Due to the diversity of tools available on the market, we are faced with the following question: which of these tools would be the most suitable to meet the needs of CTRL+E 2020? In order to answer this question a comparison case study methodology was used to explore, describe, explain and evaluate the different tools for virtual meetings and lives, according to Leão [2019] this methodology is able to capture a deep knowledge of the details of each tool. Using systematic observation as Medeiros [2019] suggests, and using resources such as desktops, notebooks and smartphones, the following video conferencing and video transmission tools were tested: Zoom Meeting, Google Meet, GoToMeeting, Cisco Webex, V4H, TeamLink, Jitsi Meet, StreamYard, Restream, ON24 and OBS Studio. The evaluation period was from 1st of May 2020 until 30th of Jun 2020. The procedures used were: 1. Study which tools for virtual meetings and lives were available at the moment; 2. Decide the order for testing the tools; 3 . Prepare a comparison table with the installation procedure and specific characteristics of each tool; 4. Schedule weekly remote meetings using a different videoconference tool; 5. Collect and make available the specifications and the inherent characteristics of each tool (in the shared google drive table); 6. Establish the priorities such as: sound quality, reduction noise, image quality, video recording and file sharing, number of users allowed simultaneously, need to create an account for use, software installation, and whether the tool was open or paid access; 7. A comparative method was used to choose the tools: Zoom Meeting, for recording presentations; and OBS Studio, to broadcast the event.

\section{Video recording and editing procedures for CTRL+E 2020}

Taking into account the different "technological" conditions of each participant, aiming to achieve success in the presentation/transmission of the lectures, round tables, technical sessions and demonstration sessions. We decided to record and / or edit the presentations of the 71 articles, 4 demos, 5 lectures and 4 round tables, placing them in the standard formatting, adopted by the event. Once we had decided to use Zoom Meeting to record the presentations, the recording and editing activities carried out in the period from 8th of Jul 2020 until 24th of Aug 2020. The guests and presenters for the CTRL+E were from various states in the country, including even guests from abroad. At that moment, the importance of the event was realized, and its potential to reach people independently of where they are, even in a context of social isolation. The recording of 75 works (articles and demonstrations) was made possible by using the same idea of the round robin scheduling process [Stallings, 2015] as the team performed 8-hour shifts, for 5 consecutive days, where each presenter had 30 minutes to perform 
the presentation to expose the work in 10 minutes. The lectures and round tables needed more time for recording, and 3 hours were always separated, for each of these moments. In addition, to avoid problems, lack of energy or connection on the part of the technical team, simultaneous recordings were made by the on-duty staff. A recording procedures manual has been prepared [Spohr et al. 2020], to all participants, with technical guidelines: such as video, audio and lighting quality and behavioral procedures in the event of unforeseen events. All recordings were scheduled for all participants in the virtual room of the Zoom Meetings platform.

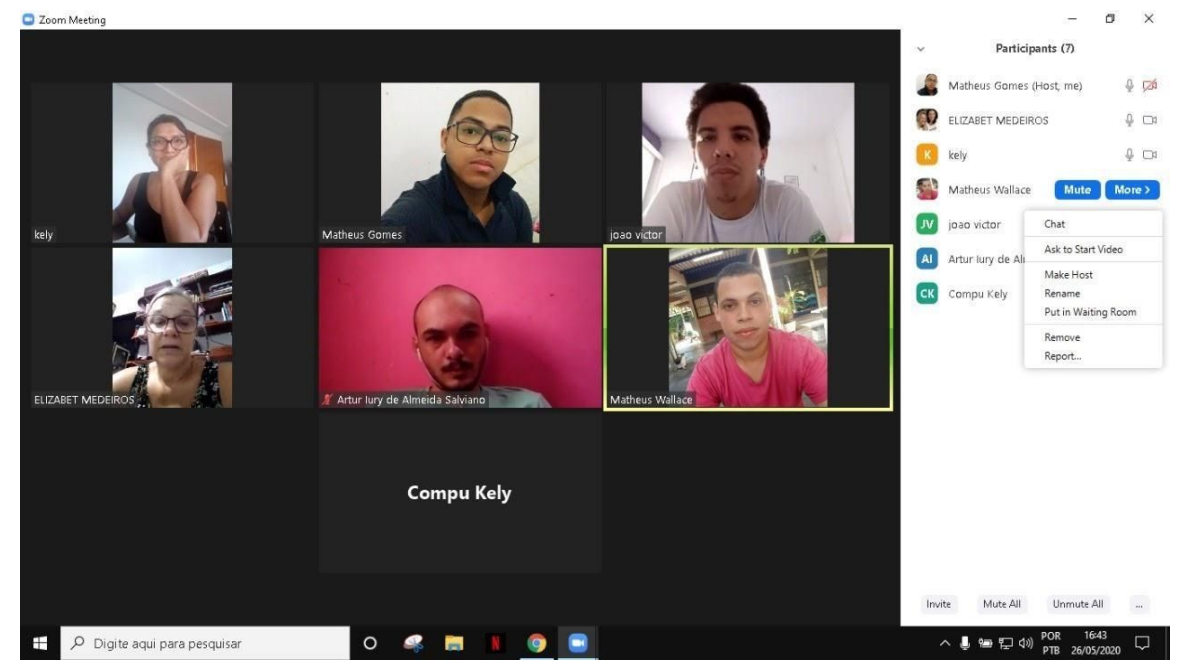

Figure 1. Testing Zoom Meetings

Regarding the editing of the videos, in addition to putting them all in the standard formatting adopted by the event, it was necessary to edit to remove any problems (speech errors, external noise, etc.) and/or something that could harm the work presented.

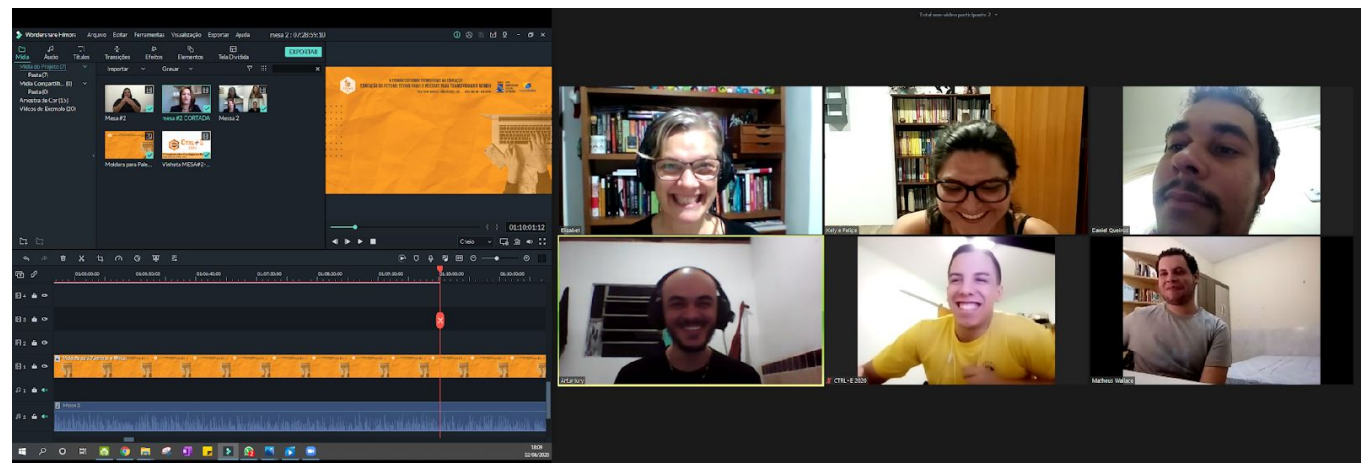

Figure 2. Working on editing videos in standard CTRL+E formatting

In this phase, synchrony and engagement were essential, since there was a high demand for a short period of time, using two platforms: Active Presenter enabling the screening of media material, and Filmora, which had refinement purposes and completion, due to its greater functionality, practicality and quality. 


\section{Formatting and transmitting CTRL+E 2020 videos and lives}

According to Gil [2019] "exploratory research aims to provide greater familiarity with the problem, in order to make it more explicit", for this reason we used exploratory research to find some softwares for recording videos and transmitting videos in real time. OBS Studio, a free and open source software, was chosen to carry out the transmissions. It was necessary to study how to create the transmission scenes, there was also a need to create interval videos and a countdown scene with music to better manage the transmission of the Lives. All 4 days of live broadcast were scripted at OBS Studio, as the format of the event required synchronous activities with retransmission of lectures and demonstration sessions followed by the participation of speakers and authors. These participants met in a virtual room of Zoom Meetings and in OBS Studio a scene was created, with the meeting window in Zoom, which, in due time, was transmitted directly to the YouTube channel.

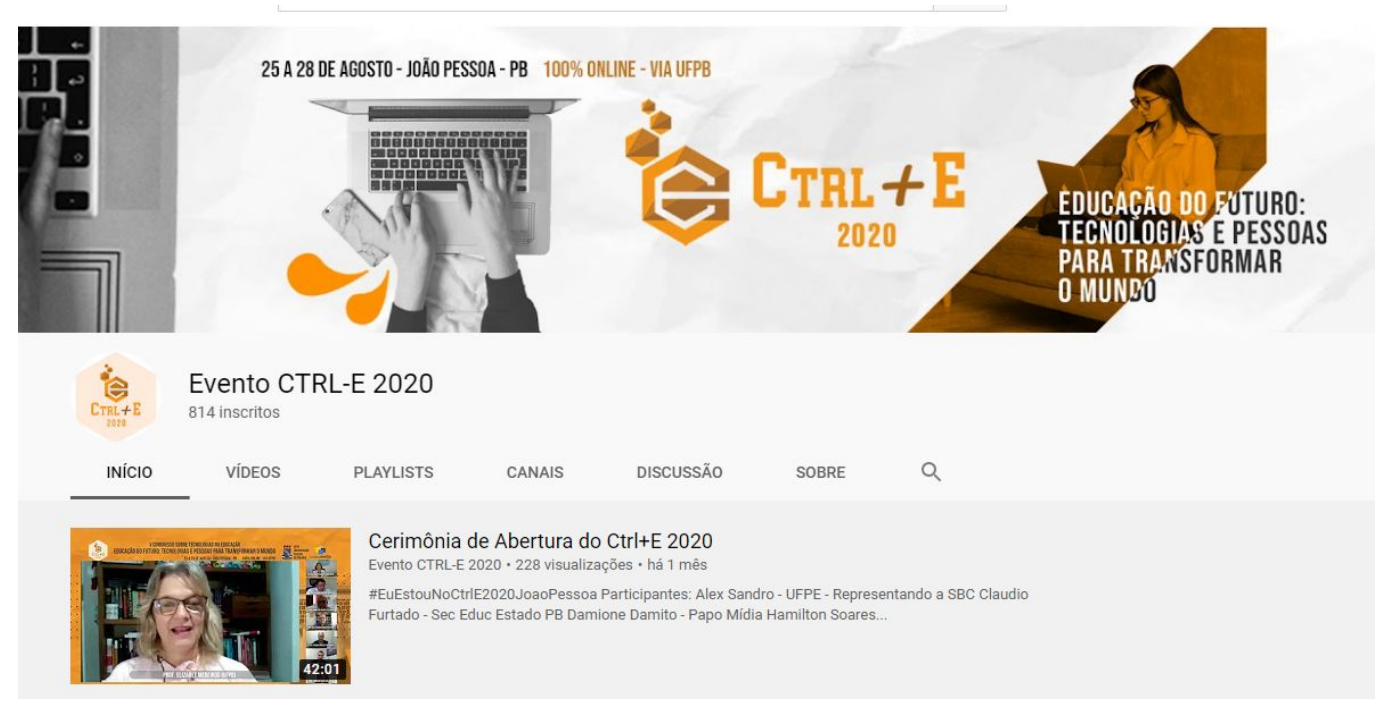

Figure 3. The CRTL+E 2020 YouTube channel

It was necessary to learn how to manage the YouTube Channel [CTRL+E 2020 YouTube channel] to organize the videos, transmit the Lives and follow the statistics. The Congress channel on YouTube had 813 subscribers, 19,648 views added and the peak of 185 simultaneous views on a single Live. The most viewed and most liked video by internet users obtained 1208 and 193 respectively (data obtained on the channel, so far). As a result, CTRL+E 2020 was carried out online, with quality transmission and with minimal complications, thanks to the problem management procedures adopted and obtained a positive evaluation by all participants.

\section{Conclusions}

The experience of transforming CTRL+E 2020 into a 100\% online event, enabled a challenge that stimulated curiosity and interest in acquiring new knowledge: academic (using scientific methodologies and procedures), technical (about the different virtual communication tools) and behavioral (which contribute to academic training and professional). In addition, with one of the greatest interaction between the academic 
communities of higher education, where the various regions of Brazil participated in the event through the platforms: YouTube, Slido and Moodle, bringing their doubts, opinions and praise, leaving the entire event committee excited for achieving this feat, as well as the presenters encouraged to discuss and reflect on their work with popular participation. In addition, the event was taken to a podcast [CTRL+E 2020 Podcast] thanks to a partnership with Papo Mídia company.

Furthermore, since the event aimed to show how technologies can be used to bring students and teachers together, how to turn educational ideas into technological achievements, from this learning, it was possible to take CTRL+E 2020 to the community.

As experience it can be said that it was a great learning experience, it was necessary to deal with great responsibilities to avoid any type of error, since the event was happening live on YouTube, in addition, it was also necessary to learn to use unknown tools such as OBS Studio, Filmora, in addition to having to manage live videos on Youtube. The experience of dealing with the pressure to set up OBS Studio and perform the live broadcast, pre-organize scenes and learn to change them at the exact moment of the broadcast, was very challenging. Teamwork helped to understand the cooperative way, where one helps the other in various problems, strengthening the team and the performance of all.

\section{References}

Bezerra, A. C. V., Silva, C. E. M., Soares, F. R. G. and Silva, J. A. M. (2020) "Fatores associados ao comportamento da população durante o isolamento social na pandemia de COVID-19". Ciência \& Saúde Coletiva, 25 (Supl. 1), 2411-2421. https://doi.org/10.1590/1413-81232020256.1.10792020.

Correia A.P., Liu, C. and Xu, F. (2020) "Evaluating videoconferencing systems for the quality of the educational experience", Distance Education, 41(4): 429-452, DOI: 10.1080/01587919.2020.1821607.

CTRL+E 2020 homepage (2020). http://ctrle.ci.ufpb.br/

$\begin{array}{lllll}\text { CTRL+E } & 2020 & \text { YouTube } & \text { channel }\end{array}$ https://www.youtube.com/channel/UCJ6qjuL3WtU-yD_L5MwZoew

$\begin{array}{llll}\mathrm{CTRL}+\mathrm{E} & 2020 & \text { Podcast } & \text { page }\end{array}$ https://www.spreaker.com/show/ctrl-e-2020-congresso

Gil, A. C. (2019) “Como Elaborar Projetos de Pesquisa” 6 ed. São Paulo: Atlas

Leão, L. M. (2017) "Metodologia do Estudo e Pesquisa: facilitando a vida dos estudantes, professores e pesquisadores" Petrópolis. RJ: Vozes

Medeiros, J. B. (2019) "Redação Científica: prática de fichamentos, resumos, resenhas" 13. ed. São Paulo: Atlas

Pires, R. R. C. (2020) “Os Efeitos Sobre Grupos Sociais e Territórios Vulnerabilizados das Medidas de Enfrentamento à Crise Santitária da COVID-19: Propostas Para o Aperfeiçoamento da Ação Pública" IPEA Nota Técnica $\mathrm{N}^{\circ} 33$, 
https://www.ipea.gov.br/portal/images/stories/PDFs/nota_tecnica/200408_nota_tenic a_diest.pdf, January 2021.

Porpiglia, F., Checcucci, E., Autorino, R., et al. (2020) "Traditional and Virtual Congress Meetings During the COVID-19 Pandemic and the Post-COVID-19 Era: Is it Time to Change the Paradigm?", Eur Urol, 78(3):301-303. DOI:10.1016/j.eururo.2020.04.018.

Spohr de Medeiros, E.M., Villacorta, K. D. V., Moreno, F. A.G., Salviano, A. I. A., Silva, M. G., Pedrosa, J. V., Cavalcanti, D. Q. and Nascimento, M. W. T. (2020). "Manual de procedimentos de Gravação para o CTRL+E 2020"

Stallings, W. (2015) “Operating Systems: Internals and Design Principles" [S.1.]: Pearson. ISBN 978-0-13-380591-8 